\title{
An approach to developing independent learning and non-technical skills amongst final year mining engineering students
}

\author{
C.G. Knobbs and D.J. Grayson
}

\begin{abstract}
There is mounting evidence to show that engineers need more than technical skills to succeed in industry. In this paper we describe a curriculum innovation in which so-called "soft" skills, specifically inter-personal and intra-personal skills, were integrated into a final year mining engineering course. The instructional approach was designed to promote independent learning and to develop non-technical skills, essential for students on the threshold of becoming practising engineers. Three psychometric tests were administered at the beginning of the course to make students aware of their own and their classmates' characteristics. Substantial prescribed reading assignments preceded weekly group discussions. Several projects during the course required team work skills and application of content knowledge to real-world contexts. Results obtained from students' reflection papers, assignments related to “soft” skills and end of course evaluations suggest that students' appreciation of the need for these skills, as well as their own perceived competence, increased during the course. Their ability to function as independent learners also increased.
\end{abstract}

\section{Key Words}

Non-technical (soft, people, social) skills/; Psychometric tests; Groups/teams; independent learning.

\section{Introduction}

Across the world there is widespread recognition that a successful $21^{\text {st }}$ century engineer requires not only technical knowledge and skills but also a range of interpersonal and intrapersonal skills. Howard Gardner (1983, p.9), father of the theory of multiple intelligences, defines interpersonal intelligence as, "the ability to understand other people: what motivates them, how they work, how to work cooperatively with them." Intrapersonal intelligence is, "a correlative ability, turned inward. It is a capacity to form an accurate, vertical model of oneself and to be able to use that model to operate effectively in life." Taken together, these intelligences form part of “emotional intelligence” (Goleman 1995).Skills 
associated with emotional intelligence include communicating effectively, working well in a team and dealing successfully with conflict.

Sadly, numerous studies attest to the fact that these social skills are often lacking amongst newly graduated engineers. For example, Bodmeret al (2002) report on a survey carried out in Europe and the United States in which 1372 engineers with degrees or diplomas rated competencies in order of importance as they affected performance. The largest gaps in competencies, measured by knowledge and skills learnt in university relative to those required in the workplace, were in communication, leadership and social skills. In Australia, Nair et al (2009)investigated gaps between education and workplace needs as identified by 109 engineering employers. The largest gaps were in the areas of communication, problem solving, teamwork and application of knowledge in the workplace. Rugarcia et al (2000) noted that engineering graduates worldwide are deficient in communication and teamwork skills.

In recognition of the importance of social skills, engineering accreditation bodies across the world are specifying that proficiency in these skills should be a requirement for graduation. In the United States, in order to be accredited by the Accreditation Board for Engineering and Technology(ABET)engineering programmes must demonstrate that their students attain, amongst other outcomes, an ability to function on multidisciplinary teams and an ability to communicate effectively (Abet Accreditation: Criteria, Policies and Procedures http:// www.abet.org accessed 1 December 2011). According to the framework for the European accreditation of engineering programmes, engineering graduates should be able, amongst other things, to "function effectively as an individual and as a member of a team" and "use diverse methods to communicate effectively with the engineering community and with society at large.” (www.enaee.eu/the-eur-ace-system/eur-ace-framework-standards)

In a document produced by the International Engineering Alliance (2009), one of the characteristics expected of graduate engineers is the ability to function effectively as an individual and a member of a diverse team.

In South Africa, the Engineering Council of South Africa (ECSA Registration http:/(www.ecsa.co.za accessed 1 December 2011) includes two similar learning outcomes, namely, that engineering graduates should, "Demonstrate competence to communicate effectively, both orally and in writing, with engineering audiences and the community at 
large” and "Demonstrate competence to work effectively as an individual, in teams and in multidisciplinary environments.”

In order to promote the development of the University of Pretoria's mining engineering students' social skills several non-technical components were explicitly included in a final year course on underground mining, Mining 410.Elements of the course were also designed to promote independent learning. We predicted that the curriculum intervention would lead to improved social skills for the students, without compromising students' technical knowledge. Self-reports from students and final course grades suggest that our predictions were correct.

\section{Description of the Course and Students}

The regulation time for a Mining Engineering degree in South Africa is four years. At the University of Pretoria the degree comprises 632 credits (each credit represents 10 notional hours of study).Mining 410 is a first semester module in the final $\left(4^{\text {th }}\right)$ year and counts for 16 credits out of a total of 156 credits for the year. The first author was the instructor in the class of 31 students, comprising 9 white males, 10 black females and 12 black males. Although the course is given in English,no student came from an English-speaking home - an African language or Afrikaans was spoken. All students had taken English as a subject in their secondary education.

The expected student outcomes for the course were: (1) to acquire and apply knowledge of the most commonly used underground mining methods, (2) to acquire knowledge of the fundamentals of management and leadership, (3) to develop key non-technical skills need to function effectively as an engineer, and (4) to improve reading, writing and speaking skills in English. Development of students' non-technical skills is related not only to outcome 2 but also to outcome 3, since good interpersonal and teamwork skills are central to good management and leadership.

\section{Design of the Intervention}

The specific non-technical skills that the intervention targeted were:

Intrapersonal (self-awareness, assertiveness)

Interpersonal (empathy, relationships and communication)

Teamwork (group dynamics and conflict handling). 
The intention was to mimic as closely as possible the intrapersonal and interpersonal issues students would face in the real world. The first author worked in industry for over 40years and so has extensive knowledge of these issues. Since the engineering curriculum is already overcrowded, the non-technical skills were integrated into the curriculum together with the technical content, as opposed to being isolated add-ons.

An approach used by the US army in training officers at West Point was used as a guiding framework for designing the modified course. This approach has three components- “being”, “knowing” and “doing” (Snook 2004). "Being” refers to an individual’s values, attitudes, beliefs, strengths and weaknesses, and the ability to reflect, introspect, and act ethically. "Knowing", is the technical or "hard" knowledge of the course or profession. "Doing" is the ability to execute and deliver and the ability to work effectively with people."Knowing” about rock mechanics and how to design a deep level mine does not prepare an individual to “do” or execute the project. Without “doing” skills, "knowing” is of limited value.

In order to address the "being" component, three psychometric tests were administered to the students, namely, the Herrmann Brain Dominance Instrument (HBDI),Shadowmatch Instrument (SI) and Myers-Briggs Type Indicator (MBTI) test. The HBDI and MBTI test are well-known and widely used, while the SI was developed in South Africa and is relevant for the local context. The HBDI identifies individual thinking preferences. The SI enabled us to compare student habits/behaviours (individual and group) with the profiles of successful engineers and managers in the industry. The MBTI test measures temperament type. Taken together, the results of these three tests provided students with a multi-dimensional understanding of themselves and their peers. The three tests are described briefly below.

\section{The Herrmann Brain Dominance Instrument (HBDI)}

The HBDI measures how a person thinks about the world in relation to four quadrants of the brain: two quadrants on the left (A and B) and two on the right (C and D) (Herrmann 1996). The A quadrant deals with logical, rational and quantitative matters; the B quadrant focuses on organisation, sequence, procedure and method; the $\mathrm{C}$ quadrant is all about emotion, expression and interpersonal issues; the D quadrant focuses on visual, conceptual and experimental dimensions. 


\section{Shadowmatch Instrument}

The Shadowmatch instrument, a South African tool, measures the behavioural habits of individuals (de Villiers 2009). It compares or matches the individual's profile of habits with the 'shadow' profile of successful mining engineers in the industry. Shadowmatch also provides development programmes for those who want to learn specific habits to enhance their prospects for success in a particular environment.

\section{Myers-Briggs Type Indicator (MBTI) Test}

The Myers-Briggs Type Indicator MBTI test (Myers \& Myers 1995), rooted in Jung’s theory of psychological types, measures temperament using four pairs of preferencesextrovert/introvert, sensing/intuitive, thinking/feeling and judging/perceiving. The MBTI is useful not only for increasing students' self-awareness but also for helping them recognise that there are others in the world who have different ways of functioning. This, in turn, is helpful background knowledge when working in a team.

All thirty-one students completed the HBDI, Shadowmatch and MBTI questionnaires at the beginning of the semester. The reason for administering these tests was to help students consider the question 'Who am I?' and to understand 'Who are you?' when interacting with their fellow students. From the three questionnaires profiles were compiled for each student.

Interpretation of results and their significance were discussed with the classas a whole and individually in most cases. Students were eager to understand the significance of the results and how critical or otherwise these might be in their careers. A typical question was, "How does an introvert (MBTI) short on C quadrant (HBDI) dominance make a success of a career in an industry requiring strong 'people' skills?’ The ability to operate outside the profiles was carefully explained and vigorously discussed in class. In addition, the Shadowmatch results compared students' profiles of habits with the profiles of a selected group of successful middle mining managers and the "shadow" of a group of consulting engineers (both groups consisted of qualified mining engineers) in the South African mining industry with 10 years of experience. Feedback was given in class and privately where requested.

The Mining 410 course consisted of five sessions a week of 50 minutes each for the twelve weeks of the semester. The dominant teaching approach comprised assigned readings and group work. This approach promoted independent learning and teamwork. Results of the 
psychometric tests, together with race and gender, were used in assigning students to heterogeneous groups.

Initially groups of 5 to 6 members were formed but found to be ineffective, whether for teaching and learning technical knowledge or developing non-technical skills. There were too many instances of non-involvement. The large teams concealed those who were not participating. After a month the groups were reduced to 3 to 4 members for the remaining themes of the course, which is in line with Felder et al's (2004,11-12) recommended group size.

Reading material relating to the subject for the week ahead was posted on the university's web-based course management system, ClickUP, for students to download and read in their own time. This material, sent on a Thursday or Friday of the preceding week, consisted of published papers (mainly from monthly publications of the two Managers' Associations in the South African mining industry), presentations from experts, such as shaft sinking contractors and De Beers on diamond mining, lecture notes (the author's own and from previous lecturers), references to chapters in a prescribed textbook (Hustrulid\& Bullock, 2001) and material from the Internet describing the more abstruse aspects of mining methods. Students were expected to familiarise themselves with the material and be prepared for the discussions the following week. The week would start with a full class discussion and a minilecture of about 20 minutes. The class would then break up into their assigned groups and move to the discussion rooms where different issues and questions, as identified in the full class, were debated for 30 minutes. After that each group would make a short presentation of 20 minutes on the group's findings. Unresolved or unsatisfactorily resolved issues from the small groups involving understanding or interpretation were discussed and debated in the full class after each presentation.

In both the small groups and the full class students were "coached" through the discussion and helped to think through the issues rather than given pat answers. The training in nontechnical skills focussed on intense discussion, interaction and feedback sessions, with individuals, groups and the whole class. Since the instructor is a trained and experienced executive coach, he made use of a large array of coaching techniques and skills. Situations of conflict were handled through constructive mediation. Two written assignments required students to reflect on the acquisition and importance of non-technical skills (see section 4). 
PowerPoint presentations were reduced to a minimum by teacher and student. Three assignments covering two mini-designs and a critique of an existing design were completed in the semester. These assignments required the submission of reports which, in turn, formed the basis of presentations with marks allocated for content and quality of presentations. Peer reviews were introduced for these assignments. Marks were allocated for group performance and individual contribution based on the peer reviews. The technical content of the course was assessed by means of regular, short class tests (eight in all), three longer assignments, two semester tests and an examination at the end of the semester.

\section{Results}

Students wrote a short Reflection paper in the middle of February 2010, three weeks after the start of the semester and the administering of psychometric tests. They were asked, "What do you think about using small groups to promote learning and develop 'soft' skills? How do you feel about this approach?” In general, students saw the benefit of learning "soft” skills because of their relevance to management. However, one student thought the technical and soft skills components should be offered in different courses, not integrated. He was particularly rigid in his viewpoint:

"This subject is supose [supposed] to be mining methods with [which] is a purely academic subject. Writing this what I'm doing right now is like sitting in a phycology [psychology] class. I don’t like it.” (This reaction could have been predicted from his HBDI profile - low B and C quadrant scores).

The written responses showed that $45 \%$ of students wanted more input from the lecturer, as illustrated by the quotes below:

“...the important things or points to note are not highlighted, so it’s really confusing."

"I feel discussions are the better part of what we do during contact time. I would also appreciate the lecturer's input in a form of summary on the work we do in class.”

"I'm worried that I might not study the supplied documents with focus on what I’m going to be tested on.” 
“...I don’t like the idea of the student learning [from] each other...We don't know what we don't know.”

A number of students commented on the teaching approach. A concern raised by $25 \%$ of students was the amount of reading they were required to do on their own. Up to this point in their academic lives, the dominant mode of teaching centered on presentation of information in lectures, followed by individual assignments. Little independent reading had been required of them, so having to read 15-30 pages a week was arduous (especially since most of the students did not speak English as their mother tongue) as illustrated below:

"I feel overwhelmed by the amount of work and become scared that I might not complete reading all documents by test week.”

Twenty-five percent of the students were uncomfortable with the inductive teaching style being used and requested clear outcomes for the course upfront:

"I feel the objectives must be set, as to what we must know after every chapter or topic, because without the objectives I feel I am just shadow-boxing while studying.”

On the positive side, 55\% of the students commented that they liked group work:

"I think the group stuff is cool, we get to argue in your absence and that's very beneficial”

"I like the group discussions because we share different ideas and we get to learn how other people think, which grows me and others as individuals. It also adds value to our cooperative skills.”

Forty percent said they enjoyed the interactive teaching style:

“I feel happy that the atmosphere in class doesn’t hinder me from asking questions when I don't understand something and when I ask I'm not made to feel less intelligent.”

"I get renewed energy. This is due to the manner in which the course is presented.”

In mid-March, a month after writing the Reflection paper, students were given three published papers to read on the importance of non-technical skills for engineers and asked to give an opinion on the contents. The assignment was to write a short Opinion paper to 
“summarise the three articles' approach to 'soft skills' and express your opinion on the authors’ findings.” Their opinions are analysed as follows: 70\% of the class agreed on the need to teach or help develop non-technical skills in the course as an integrated adjunct to the teaching of technical knowledge while 30\% disagreed or had reservations. Interestingly, $80 \%$ of the female students showed enthusiasm for learning about soft skills and working in small groups whereas only $65 \%$ of the males concurred. A number of students recommended that these skills be taught from the first year of university study. The importance of soft skills in furthering their careers was acknowledged. Working in groups in order to foster nontechnical skills was accepted but with the reservation that groups needed to be helped to

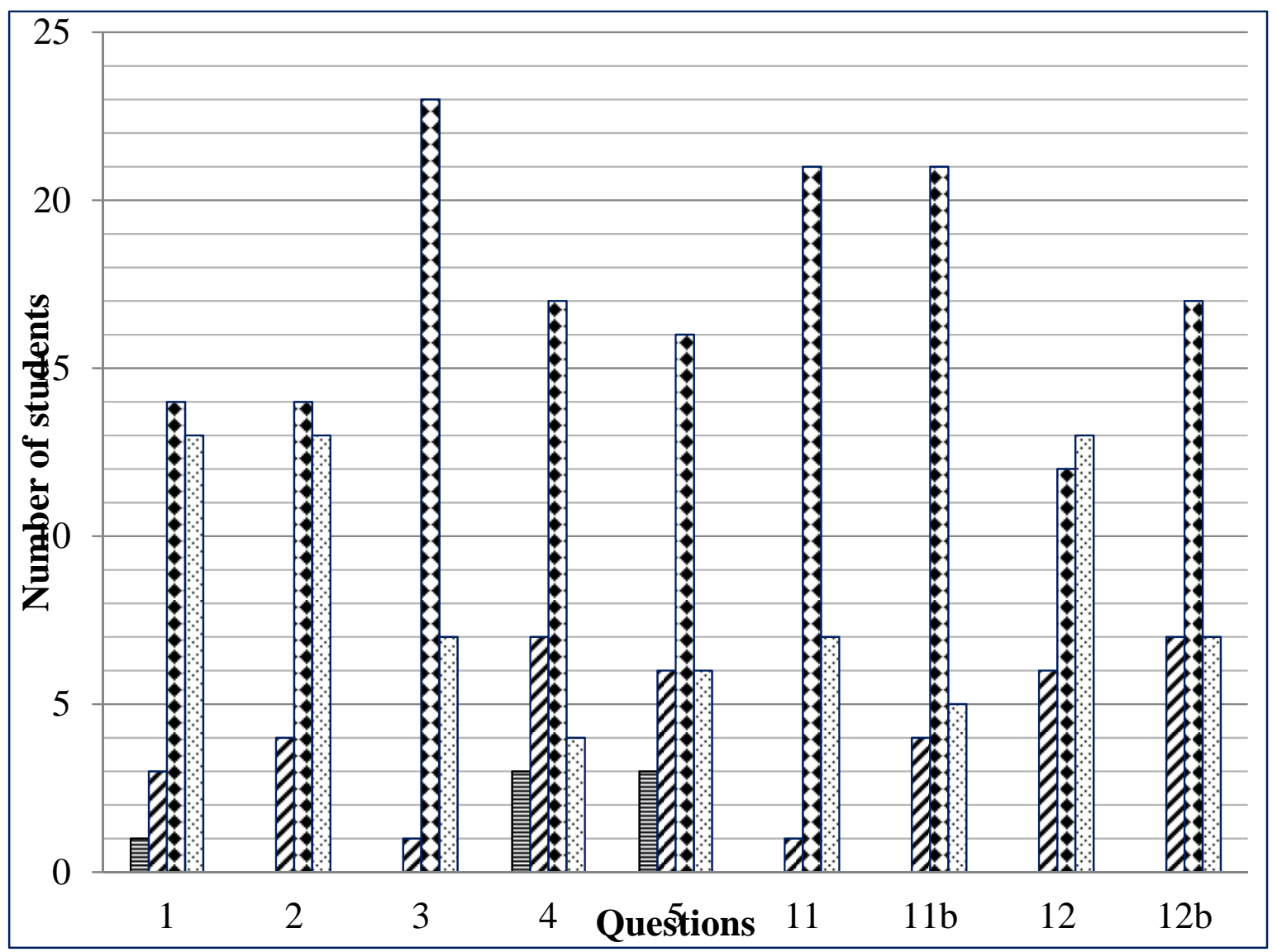

Figure 1: Responses to questions 1 to 5 and 11 and 12 on the end of semester questionnaire. For each question, the left-most bar corresponds to the most negative response and the right-most bar to the most positive response. 
function effectively as teams ("putting people into groups does not mean that the group will be effective”). A concern was raised that working in teams was overemphasised at the expense of working alone on technical matters ("there needs to be a better trade-off between team work and individual work, and soft skills and technical skills”). Furthermore the problem of "non-performers" had to be addressed ("there is always someone not doing any work and just riding on the back of the group, always late and wasting time”).

At the end of the semester (May) the thoughts, perceptions and opinions of students with regard to the group process as a teaching strategy for technical and non-technical skills were measured. A questionnaire was constructed (Appendix) comprising 23 questions, 17 that required structured responses and 6 open-ended responses. Each structured question used a 4point scale, ranging from very favourable to very unfavourable. A summary of the responses to the structured questions is shown in Figures 1 and 2, with the most negative responses shown on the left and most positive on the right for each question.

From Figure 1 it can be seen that most of the students found that the approach used in the course helped their:

Knowledge and understanding (Q1)

Design skills (Q2)

Ability to think more broadly about engineering (Q3).

While the majority of students enjoyed working in small groups (Q4) and said that it enhanced their learning (Q5), nearly one third were not positive about the small group experience. This also came out in response to question 7.

In terms of personal skills and attitudes, Figures 1 and 2 show that most students' confidence and ability in communication in both small and large groups improved (Q12,13), as did their self-worth (Q14). Problem-solving ability (Q15), teamwork and interpersonal skills (Q17) also improved for most students. All but three students reported that the HBDI and Shadow Match psychometric tests helped them better understand both themselves and others (Q18). 


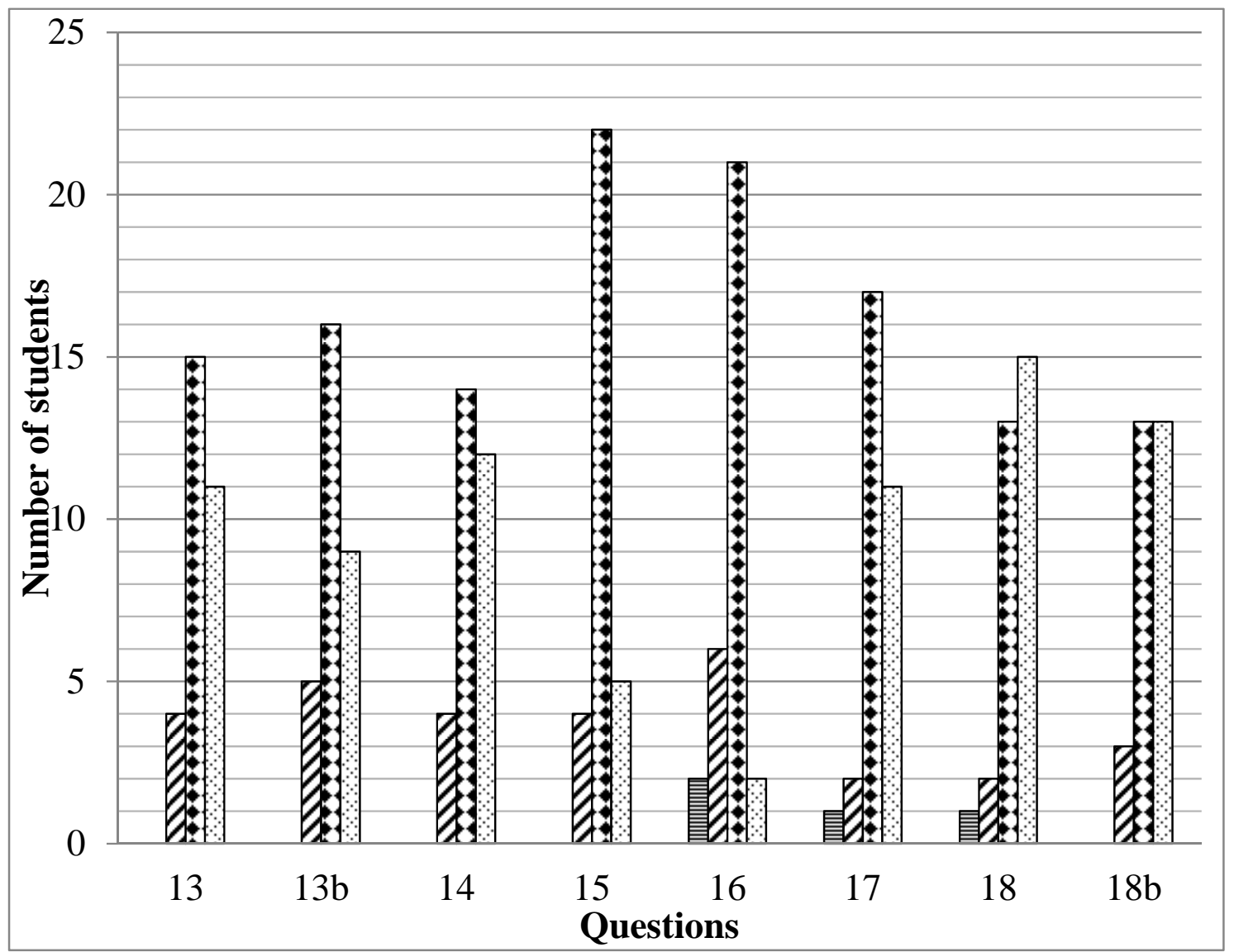

Figure 2: Responses to questions 13 to 18 on the end of semester questionnaire. For each question, the left-most bar corresponds to the most negative response and the right-most bar to the most positive response.

In the open-ended questions, in response to Question 6, "What aspects of the course did you enjoy?” a number of students valued interacting with their peers and actively participating, as illustrated by the quotes below:

"Working in small groups, this gave me a chance to communicate with fellow students and to change ideas".

"I enjoyed the class interactions aspect.It always kept me awake and aided me in learning many industry standards from other students”.

“The part where we were given a problem and had to design something. This made us more aware of what to expect and how interesting our work will be”.

Several students indicated that they enjoyed the whole class discussions with the lecturer, as illustrated below: 
"The interaction between students and the lecturer was much better than from previous modules. Very comprehensive, conceptual presentation from the lecturer”.

"Being able to share my knowledge with the class without being made to feel 'dumb'.Learning from others in a free (didn’t doubt others or ourselves) environment”.

"The open discussion we had in class; with both the lecturer and our colleagues. The ability to ask and question anything that was presented to us openly”

On the other hand, there were some students who clearly preferred input from the lecturer to peer group learning, as illustrated below:

"Interaction with lecturer, continuous assessment means very little to learn before exam”.

"When we were actually thought (taught?) something directly from the lecture not from students; who themselves are not too sure”.

In response to Question 7, "What aspects of the course did you not enjoy?” some students thought that there was too much group work or that some group members did not contribute enough, as illustrated below:

“There was too much working in groups, and not enough knowledge sharing from the lecturer himself”.

“Being in groups and not actually getting any work done by group members”.

“Obtaining 'poor' marks in group work because of inconsistent group participation and knowledge”

"Having to work in groups and not everyone bringing their part to the work"

Both student comments and our own observations suggest that the groups did not always function well in promoting peer learning. Improved group functioning could probably have been achieved if we had applied the principles of cooperative learning (Johnson et al, 2006), particularly the element of group processing. In addition, some students encountered challenges in working in a diverse group, something they will have to learn to cope with in the workplace: 
“At times the group work was not a helpful learning tool because you find that as a group we know equally as little about the topic. It was frustrating and it really did not enhance learning”.

“Too much group work can sometimes lead to complete inefficiency. Moderating between group work and individual work could help make the new approach much better”.

"It was sometimes difficult (but helpful) to work in groups from different cultures/backgrounds.

Some students also indicated that they struggled with the amount of reading and a perceived lack of direction:

"Not enough specific direction, too broad which is insufficient to the aspects of the module”.

"Discussions were good but at the beginning they were a bit too much. And the articles we had to go through were overwhelming at times”.

In response to Question 8, “What topics should be added to the course?” about half of the class mentioned technical aspects and a need for management, leadership and people skills. In response to Question 9, “What aspects should be removed (or modified) in the course?”, about half of the class were happy with the course as it stood, while the other half mentioned their disquiet over the inclusion of a certain mining method (shrinkage stoping) not widely practised. Three students commented negatively on the interpersonal and intrapersonal elements of the course:

"HBDI, Shadowmatch. This is mining methods. If we want those things done we would do it at our own time if we want”.

"Less human interaction-it is vital I agree but maybe a lecture in a week is vital to give a clear direction, because is quite a radical change from a normal way of lecturing to groups”.

"Group discussions during class time; rather just on assignments because there is not much we learn from each other”

In response to Question 10, "What can be done to improve the course?” negative comments about the group work again appeared. Some students maintained that they could not learn adequately from one another and needed the lecturer to supply the "right" answers: 
“After a discussion, give the right answer.”

"Reducing the team discussion sessions, to maybe one per week and not everyday.”

"Group discussions are good, but at the end of the day there should be a thorough input of how the group should have answered."

"A conclusion from the lecturer at the end of each discussion session could get rid of all the confusion many students have.”

“The lecturing method was improvement on its own; I believe now improvement has to be focused on the team/groups to make sure everyone participates to their maximum ability.”

“A bit of lecturing would help, not too much, just as an introduction.”

Responses to Question 19, "What else do you want to tell me about the course or yourself?”, were generally positive:

"One of the best presented course in the department, I got to learn a lot of things."

"The course has helped me [to] think out of the box, think of the big picture and think on my feet. It (the thinking) will definitely be used in mine design.”

"As someone who was repeating the course I can say that the new approach is good and it will also be much better when applying what we have learnt for mine design.”

“The holistic approach of looking at a design is one thing that I have learnt through this course. Engineering had turned me into a stereotype with a systematic approach to solving solutions but seeing the bigger picture has made me a better student.”

"I really enjoyed the course because it was very well managed."

"I think the course should be presented the same way even for the coming years. A lot was learnt not just from theory but from fellow students as well.” "I enjoyed attending a class in which my ideas were not deemed dull, even when I was wrong, but corrected. It built the willingness to share knowledge with others and to learn from others.” 
There were some detractors confirming responses to earlier questions:

“The approach was good even though at times it felt like we [are] over loaded with too much work.”

"All in all, the course was enjoyable although it required a lot of time for self study and group work.”

“The course was broad and I think it needs a little more focus on key issues." "I believe the approach was a brilliant one. There are however few things that could be modified to better enhance it. Giving conclusive remarks could be one of them.”

“The large amount of group assignments can be overwhelming. Remember that we have other subjects as well. We must rather have more individual projects, and one or two group assignments.”

Students' improvement in soft skills was not measured objectively. However, discussions in class and privately, listening with the "third ear", observation and intuition gave the first author some indication as to how students were faring. In the second semester regular group coaching sessions included in another course, Mine Design, produced valuable insights into students' improved abilities to work effectively in small groups on a design project. Students attributed these enhanced abilities to their exposure to group work in the Mining 410 course of the first semester.

\section{Conclusion}

As a result of changing demands of the workplace, engineers need both non-technical and technical knowledge and skills in order to be successful in the $21^{\text {st }}$ century. Furthermore, the rapid rate at which knowledge is growing and changing makes it essential for engineers to be able to learn independently. In this paper we have provided an example of how the development of a number of non-technical and independent learning skills can be integrated into a mainstream module for final year mining engineering students. The course was designed around the three outcomes of "being”, "knowing” and “doing”, where "being” pertains to self-knowledge, "knowing" is related to discipline knowledge and "doing” relates to application of knowledge within a social context. 
The main strategy for promoting independent learning was to prescribe extensive reading assignments that had to be completed prior to coming to class, followed by intensive peer interaction and coaching. Intrapersonal skills were developed primarily by means of three psychometric tests, namely, the Hermann Brain Dominance Instrument, Shadowmatch and the Myers-Briggs Type Indicator. Written papers requiring reflection also promoted metacognition. Interpersonal skills were developed by having students work in groups that were heterogeneous in terms of race, gender and psychometric profiles for much of the class time.

Results of written papers and an end of course evaluation showed that nearly all of the students thought that the instructional approach lead to an improvement in both their nontechnical skills and their technical knowledge and understanding. While we cannot make a comparison with students' attitudes to other instructional approaches, it does appear that students do not feel that their acquisition of technical knowledge was compromised by our approach. There were only 4 of 31 responses per question that were consistently less than positive. The aspects for which the largest number of students responded "extremely enhanced/enjoyable/helpful” were: knowledge and understanding of the course material, design skills, confidence in communication in small groups, self-worth, teamwork and interpersonal skills, and the value of the psychometric tests in understanding themselves and others.

A recurrent complaint by a number of students pertains to the balance between group work and formal input from the lecturer and the functioning of the groups. Students would prefer more direction from the lecturer and summary of important points. They expressed concern that sometimes none of them understood the work well and so they could not learn effectively from each other. They were also not always able to identify important points from the many pages of prescribed reading.

According to Johnson and Johnson (2011), extensive research into cooperative learning, with its high reliance on group work, has shown that this instructional approach leads to high achievement, quality of relationships and psychological health. In our intervention, although there were benefits to group work, the functioning of the groups could be improved. In future, elements of cooperative learning should be introduced, including providing more information about group dynamics, together with advice on how to deal with conflict, uncertainty, frustration and non-performance. An assessment of individual participation and 
performance should also be included, which should be considered by the group in open discussion. In Johnson et al.’s (1994) terms, the progression from elementary group skills like 'forming' and 'functioning' to more advanced interpersonal skills like 'formulating' and 'fermenting' seems to be essential in preparing and consolidating collaborative skills for effective group work. According to them,

"Nothing we learn is more important than the skills to work cooperatively with other people”. (p.75)

It may also be helpful to change the composition of the groups more frequently, perhaps once a month to coincide with the introduction of new technical themes. This would provide students with opportunities to work with other colleagues displaying different psychological make-ups.

Several students suggested that the development of soft skills and independent learning should begin in the first year of the degree. We concur, but at our university there is a common core curriculum for all engineering students for the first two years of the degree. Most of these courses are taught outside the Department of Mining Engineering. Following the success of the intervention we described, changes will be made to some third year mining engineering courses in 2012 along similar lines. In addition, a peer mentorship programme will be launched in 2012 in which senior students will mentor first year students in small groups.

In summary, we suggest that the course design and instructional approach in which independent learning and non-technical skills are developed in the context of a disciplinespecific module are both effective and desirable in preparing final year engineering students for the world of work. Furthermore, the pass rate for the course was 85\%, compared with $65 \%$ the previous year. This suggests that mastery of the technical component, far from having to be compromised, was enhanced.

\section{References}

Accreditation Board for Engineering and Technology (ABET), Criteria for Accrediting Engineering Programs, Effective for Evaluations during the 2010 - 2011 Accreditation cycle, Baltimore, MD. 
Bodmer,C., Leu,A., and Rutter,H. (2002) SPINE: Successful Practices in International Engineering Education: Engineers Shape our Future IngCH

De Villiers, P. (2009). Shadowmatch: The Full Story. DBA, Bryanston, South Africa.

Felder, Richard M., Oakley, Barbara., Brent, Rebecca., and ElhajjImad. (2004). Turning Student Groups into Effective Teams. Journal of Student Centered Learning, Volume 2 No.1, $11-12$

Gardner, H. (1983). Frames of Minds: The Theory of Multiple Intelligences (repr,2006).The Perseus Books Group, New York, NY.

Goleman, D. (1995). Emotional Intelligence. Bloomsbury, London.

Herrmann, N. (1996). The Whole Brain Business Book.McGraw-Hill, New York, NY.

Hustrulid, William A., and Bullock Richard L.(2001). Underground Mining Methods Engineering Fundamentals and International Case Studies.Society for Mining, Metallurgy and Exploration, Inc., Littleton, Colorado, USA

International Engineering Alliance (June 2009). Graduate Attributes and Professional Competencies Version 2

Johnson, David W. and Johnson, Roger T. (2011), Cooperative Learning: Relationships Among Theory, Research and Practice. Part 1 Small Group Learning In Higher Education: Research and Practice. Cooper James L and Robinson, Pamela.ed New Forums, Stillwater, $\mathrm{OK}$

Johnson, D.W., Johnson, R.T. and Smith, K. (2006). Active Learning: Cooperation in the College Classroom. Interaction Book Company Edina, MN

Johnson, W.D., Johnson,R.T., and Holubec,E.J. (1994). The New Circles of Learning: Cooperation in the Classroom and School.ASCD, Alexandria, Virginia, USA.

Male,S.A., Bush,M.B.,\&Chapman,E.S. (2010). Perceptions of Competency Deficiencies in Engineering Graduates.Australasian Journal of Engineering Education, Vol.16 No 1 
Myers,I.B., \&Myers,P.B. (1995). Gifts Differing.Understanding Personality Types.Brearley, Nicholas Publishing, Boston

Nair, C. S.,Patil,A., \&Mertova, P. (2009), “Re-engineering graduate skills - a case study”, Eur. J. Eng.Ed., Vol. 34, No 2, 131-139.

Rugarcia, A., Felder R.M., Woods D.R., \&Stice, J.E., (2000) The future of Engineering Education - A vision for A New Century. Chem.Eng. Education, 34(1): 16-25.

Snook, S.A. (2004), “Be, Know, Do: Forming Character the West Point Way,” Compass: A Journal of Leadership 1: 16-19, 38. 
APPENDIX

\section{PMY 410 Feedback questionnaire 10 May 2010}

This year PMY 410 was taught completely differently to previous years. Greater emphasis was placed on small group (team) discussions and assignments, and less traditional lecturing took place. Self study was encouraged and fostered through the many presentations and papers sent to students through ClickUp. Greater participation and interaction in the larger group was also stimulated. HBDI andShadowmatch assessments were conducted to help individuals in 'knowing' themselves and others. Please answer the following questions regarding the course.

1. How do you think the new approach helped your knowledge and understanding of the course material?

\begin{tabular}{|l|l|l|l}
\hline Not helpful at all & Not too helpful & Helpful & Extremely helpful
\end{tabular}

2. How do you think it helped your design skills?

\begin{tabular}{|l|l|l|l}
\hline Not helpful at all & Not too helpful & Helpful & Extremely helpful
\end{tabular}

3. To what extent do you think this approach enhanced your ability to think more broadly about engineering and the role of engineering?

\begin{tabular}{|l|l|l|l|}
\hline Not at all & Not enhanced much & Enhanced & Extremely enhanced \\
\hline
\end{tabular}

4. How much did you enjoy working in small groups?

\begin{tabular}{|l|l|l|l|}
\hline Not at all & Not enjoyed & Enjoyed & Extremely enjoyable \\
\hline
\end{tabular}

5. To what extent was your learning enhanced by working in small groups

\begin{tabular}{|l|l|l|l|}
\hline Not at all & Not enhanced much & Enhanced & Extremely enhanced \\
\hline
\end{tabular}

6. What aspects of course did you enjoy?

7. What aspects of the course did you not enjoy? 
8. What topics should be added to the course?

9. What topics should be removed (or modified)from the course?

10. What can be done to improve the course ?

11. To what extent has the topics been presented well?

a) Material / education / content

\begin{tabular}{|l|l|l|l|}
\hline Extremely poor & Poor & Well & Extremely well \\
\hline
\end{tabular}

b) Presentation / delivery

\begin{tabular}{|l|l|l|l|}
\hline Extremely poor & Poor & Well & Extremely well \\
\hline
\end{tabular}

12. To what extenthas your confidence in communication changed:

a) for small groups

\begin{tabular}{|l|l|l|l|}
\hline Not at all & Not much & Some & A lot \\
\hline
\end{tabular}

b) for large groups

\begin{tabular}{|l|l|l|l|}
\hline Not at all & Not much & Some & A lot \\
\hline
\end{tabular}

13. To what extent has your ability to effectively communicate ideas changed:

a) for small groups

\begin{tabular}{|l|l|l|l|}
\hline Not at all & Not much & Some & A lot \\
\hline
\end{tabular}

b) for large groups

\begin{tabular}{|l|l|l|l|}
\hline Not at all & Not much & Some & A lot \\
\hline
\end{tabular}


14. To what extent did all the interaction with your fellow students and the lecturers enhance your self worth?

\begin{tabular}{|c|l|l|l|}
\hline Not at all & $\begin{array}{l}\text { Not } \\
\text { enhanced } \\
\text { much }\end{array}$ & Enhanced & $\begin{array}{l}\text { Extremely } \\
\text { enhanced }\end{array}$ \\
\hline
\end{tabular}

15. To what extent do you feel this course enhanced your problem solving ability?

\begin{tabular}{|c|l|l|l|}
\hline Not at all & $\begin{array}{l}\text { Not } \\
\text { enhanced } \\
\text { much }\end{array}$ & Enhanced & $\begin{array}{l}\text { Extremely } \\
\text { enhanced }\end{array}$ \\
\hline
\end{tabular}

16. To what extent have you presentation skills been enhanced?

\begin{tabular}{|c|l|l|l|}
\hline Not at all & $\begin{array}{l}\text { Not } \\
\text { enhanced } \\
\text { much }\end{array}$ & Enhanced & $\begin{array}{l}\text { Extremely } \\
\text { enhanced }\end{array}$ \\
\hline
\end{tabular}

17. To what extent have your teamwork and interpersonal skills been enhanced?

\begin{tabular}{|c|l|l|l|}
\hline Not at all & $\begin{array}{l}\text { Not } \\
\text { enhanced } \\
\text { much }\end{array}$ & Enhanced & $\begin{array}{l}\text { Extremely } \\
\text { enhanced }\end{array}$ \\
\hline
\end{tabular}

18. To what extent have the HBDI and Shadow Match exercises helped you better understand:

yourself?

\begin{tabular}{|l|l|l|l|}
\hline $\begin{array}{l}\text { Not helpful } \\
\text { at all }\end{array}$ & $\begin{array}{l}\text { Not too } \\
\text { helpful }\end{array}$ & Helpful & $\begin{array}{l}\text { Extremely } \\
\text { helpful }\end{array}$ \\
\hline
\end{tabular}

other people?

\begin{tabular}{|l|l|l|l|}
\hline $\begin{array}{l}\text { Not helpful } \\
\text { at all }\end{array}$ & $\begin{array}{l}\text { Not too } \\
\text { helpful }\end{array}$ & Helpful & $\begin{array}{l}\text { Extremely } \\
\text { helpful }\end{array}$ \\
\hline
\end{tabular}

19. What else do you want to tell me about the course or yourself? 